using amniocentesis and spectrophotometric scanning of amniotic fluid. Amer. J. Obstet. Gynec., 92: 341 (1965).

6. Freda, V. J.: RhoGAM Symposium, Complete Proceedings (Ortho Diagnostics, New York, 1969).

7. Hindemann, P.: Maternofetal tranfusion during delivery and $\mathrm{Rh}$ sensitization of the newborn. Lancet, $1: 46(1973)$.

8. Lalezari, P.: A new method for the detection of red blood cell antibodies. Transfusion, 8: 372 (1968)

9. Levine. P.: Influence of the ABO system in Rh hemolytic disease. Human Biol., 30: 14 (1958).

10. Levine. P., and Waller, R. K.: Erythroblastosis in the first born. Prevention of its most severe forms. Blood, $1: 143$ (1948).

11. Nevanlinna, H. R., and Vainio. T.: The influence of mother-child ABO incompatibility in $\mathrm{Rh}$ immunization. Vox Surg. 1: 26 (1956).

12. Owen, R. O., Wood, H., Foord, A. G., Sturgeon. P., and Baldwin, L. G.: Evidence for actively acquired tolerance to Rh antigens. Proc. Nat. Acad. Sci., 40: 420 (1956).

13. Pollack, W., Ascari, W. Q., Crispen, J. F., O'Connor, R. R., and Ho, T. Y.: Studies on $\mathrm{Rh}$ prophylaxis. II. Rh immune prophylaxis after transfusion with Rh positive blood. Transfusion, 11: 340 (1971).

14. Pollack, W., Ascari, W. Q., Kochesky, R. J., O'Connor, R. R., Ho, T. Y., and

Copyright (C) 1976 International Pediatric Research Foundation, Inc
Tripodi, D.: Studies on Rh prophylaxis. I. Relationship between doses of anti-Rh and size of antigenic stimulus. Tranfusion, 11: 333 (1971).

15. Ramos De Almeida, J. M., and Rosado, L.: Rh blood group of grandmothers and incidence of erythroblastosis. Arch. Dis. Childhood, 47: 609 (1972)

16. Shrarnoff, J. G., and Jasper, J. D.: Fetal hydrops. Primipara immunized by previous intramuscular injection of $\mathrm{Rh}_{\mathrm{o}}$ (D) blood: Report of a case. J. Amer. Med. Ass., 144: 845 (1950).

17. Taylor, J. F.: Sensitization of $\mathrm{Rh}$ negative daughters by their $\mathrm{R} h$ positive mother. N. Engl. J. Med., 276: 547 (1967).

18. Trichenor, C. J.: Erythroblastosis fetalis in the primipara. Clin. Proc. Women's Hosp., 3: 317 (1941).

19. Wallace, J. T., Weiner, V.S., and Doyley, M. H.: Rh sensitization in a primipara caused by intramuscular injection of human serum, resulting in fatal erythroblastosis. Amer. J. Obstet. Gynec., 56: 1163 (1948).

20. Zarou, D. M., Lichtman, H. C., and Hellman, L. M.: The transmission of chromium 51 tagged maternal erythrocytes from mother to fetus. Amer. $J$ Obstet. Gynec., 88: 565 (1964).

21. Requests for reprints should be addressed to: F. W. Bowen, Jr., M.D., MAJ MC, Department of Pediatrics, William Beaumont Army Medical Center, El Paso, Tex. 79920 (USA).

22. Accepted for publication November 10, 1975

Pediat. Res. 10: 215-219 (1976)

Folic acid

formiminoglutamic aciduria

hydantoin-5-propionic aciduria

\title{
Hydantoin-5-Propionic Aciduria in Folic Acid Nondependent Formiminoglutamic Aciduria Observed in Two Siblings
}

\author{
A. NIEDERWIESER, ${ }^{(23)}$ ANA MATASOVIĆ, B. STEINMANN, K. BAERLOCHER, AND BIANCA \\ KEMPKEN \\ Medizinisch-Chemische Abteilung und Stoffwechselabteilung, Universitäts-Kinderklinik, Zürich, Switzerland
}

Extract

Two previously described sisters with folic acid nondependent formiminoglutamic aciduria also excrete abnormally high amounts of hydantoin-5-propionic acid (HPA). HPA was identified by gas chromatography-mass spectrometry as the $N, N^{\prime}$-bis-trimethylsilyl methyl ester- and $N, O$-permethyl derivatives. About 600 and $1,100 \mathrm{mmol} \mathrm{HPA} / \mathrm{mol}$ creatinine, respectively, were found in 24-hr urine samples before and after ingestion of free histidine (three equal doses of $66 \mathrm{mg} / \mathrm{kg}$ each, with 4 -hr intervals). The corresponding values in normal adults were $4.5 \pm 2.2(n=24)$ and $46.0 \pm 16.4 \mathrm{mmol} \mathrm{HPA} / \mathrm{mol}$ creatinine $(n=17)$ when measured by a new, highly specific mass fragmentographic method using deuterated HPA as the internal standard.

\section{Speculation}

Formation of hydantoin-5-propionic acid from imidazolone propionic acid (ImOPA) by aldehyde oxidase represents a bypass at elevated concentrations of ImOPA caused, e.g., by formimino-Lglutamate:tetrahydrofolate-5-formiminotransferase (EC. 2.1.2.5) deficiency (as postulated for our cases), general or functional folate deficiency, or imidazolone propionic acid hydrolase deficiency (not yet detected). HPA excretion in urine measured by mass fragmentography may be a sensitive tool to detect such deficiencies and may complement or even replace the enzymatic measurement of formi minoglutamic acid excretion.

In 1974, we described two sisters with normal serum folate concentration who excreted formiminoglutamic acid (FIGlu) in excessive amounts (15), both about $600 \mathrm{mmol} \mathrm{FlGlu} / \mathrm{mol}$ creatinine. We believe that they represent the first cases where a practically complete deficiency of formimino-L-glutamate:tetrahydrofolate-5formiminotransferase can be postulated. Our cases did not respond to pharmacologic doses of folic acid. Recently Perry et al. (17) described two other cases with apparently the same metabolic error. They excreted markedly lower amounts of FIGlu under pharmacologic doses of folic acid. From the known catabolic pathway of histidine we also suspected an increase in the excretion of HPA (15). For the precise measurement of this compound in urine we developed a relatively simple mass fragmentographic method (16). In this report, the results of these measurements are presented.

\section{MATERIALS AND METHODS}

HPA was synthesized from L-glutamic acid according to the method of Dakin (10). Similarly, trideutero-HPA was synthesized from 2,4,4-[2 $\left.{ }^{2} \mathrm{H}_{3}\right]$-DL-glutamic acid (19). HPA was analyzed quantitatively as the $N, O$-permethyl derivative with trideutero- 
HPA as internal standard by a mass fragmentographic method (16). Gas chromatography-mass spectrometry was performed on a LBK 9000 instrument. FIGlu concentration in urine was determined enzymatically as described previously (15).

\section{CASE REPORTS (20)}

\section{$F D, L D$, AND THEIR FAMILY}

For detailed description of $F D, L D$, and their family see Reference 15 . Their brother, $T D$, as well as their sisters, $S D$ and $J D$, are healthy children. $L D$ showed no clinical abnormalities. $F D$ was admitted to our hospital for evaluation of her retardation in speech development. She was unable to integrate a critical length of successive acoustical and optical stimuli.

\section{PATIENTS WITH FOLIC ACID DEFICIENCY}

$R T$ has been treated with several antiepileptic drugs since the age of 2 months. The boy was admitted for evaluation of severe megaloblastic anemia ( $\mathrm{Hb} 3.0 \mathrm{~g} / 100 \mathrm{ml})$.

$M H$ is of small stature because of malabsorption and has normal body proportions. The child is anemic, with mild retardation in psychomotor development.

$D S$, treated with various antiepileptic drugs since the age of 1.5 years, was admitted for evaluation of a progressive neurologic disorder. Hematologic findings were normal.

\section{RESULTS}

\section{IDENTIFICATION OF HYDANTOIN-5-PROPIONIC ACID}

The presence of abnormal amounts of HPA in the urine of $F D$ and $L D$ was suggested by an intense spot moving in a manner similar to authentic HPA on a high voltage electropherogram at $\mathrm{pH}$ 4 , and stained for hydantoins with diphenylcarbazone-mercuric acetate reagent (7). The unequivocal identification was achieved by gas chromatography-mass spectrometry.

A 5 -ml urine aliquot from $F D$ was applied to a small column of Dowex $50-\mathrm{W}-\mathrm{X} 8\left(\mathrm{H}^{+}\right.$form $)$. The column was washed with excess water and $5 \%$ acetic acid. The total eluate was repeatedly eevaporated to dryness, dissolved in $5 \mathrm{ml}$ water, adjusted to $\mathrm{pH} 9$ with $\mathrm{NaOH}$, and applied to a small column of Dowex 1:X8 (acetate form). The column was washed with water (discarded) and $2 \mathrm{M}$ acetic acid. The eluate was evaporated to dryness.

For permethylation, the residue was dissolved in methanoldimethylformamide and methylated with methyliodide/tetramethyl-ammonium hydroxide (16). For esterification and trimethylsilylation, the residue was warmed in $2 \mathrm{M} \mathrm{HCl}$ in dry methanol for $1 \mathrm{hr}$ at $60^{\circ}$; after evaporation, the residue was suspended in methanol, the clear supernatant was evaporated in a small vessel, and the residue was reacted with bis-trimethylsilyl trifluoroacetamide in acetonitrile for $1 \mathrm{hr}$ at $110^{\circ}$. Gas chromatography on $1 \%$
SE-30 and other phases gave a large peak at the retention time of the corresponding authentic HPA derivative. The mass spectra (Figs. 1 and 2) could not be distinguished from the corresponding reference spectrum.

\section{HPA EXCRETION BEFORE AND AFTER LOADING WITH HISTIDINE}

The HPA values in 24-hr urine before and after loading with L-histidine for all members of the family, for patients with folic acid deficiency $(R T, M H$, and $D S)$, and for normal infants and adults are compiled in Table I. Values for FIGlu excretion are added for comparison. Oral loading with free histidine was performed as standardized by Luhby and Cooperman (13).

Before the histidine load, the girls with postulated formiminotransferase deficiency, $F D$ and $L D$, excreted a more than 50 times greater amount of HPA than the control subjects. The values for the other members of the family as well as for the cases with folate deficiency are at the upper limit of the normal range or slightly above that (mother and $S D$ ).

After the histidine load, the excretion of HPA by $F D$ and $L D$ is still doubled and tripled, respectively. With the exception of the father, the values for the other members of the family also markedly exceed the normal range, and are of the same order of magnitude as in folate deficiency.

Administration of folic acid in pharmacologic doses $(10 \mathrm{mg} / 24$ hr for 8 days) did not alter HPA or FIGlu excretion by $F D$ significantly.

With a diet low in histidine (11.2 mg histidine (His)/24 hr) the excretion of HPA by FD decreased by about $50 \%$ within $12 \mathrm{hr}$. At the same time FIGlu excretion decreased to about a fifth of the original value (15). The course of the HPA excretion after a single dose of histidine was followed in a normal woman $(100 \mathrm{mg}$ free $\mathrm{His} / \mathrm{kg}$ per os after overnight fasting); of the corrected total amount of HPA excreted, 54, 86, 96, and $99 \%$ appeared within 4 , 8,12 , and $24 \mathrm{hr}$, respectively.

An 85-year-old patient with pernicious anemia excreted HPA still within the normal range (no histidine load), but only unmeasurably low amounts after vitamin $B_{12}$ treatment.

\section{DISCUSSION}

Brown and associates $(8,9)$ first demonstrated the formation of HPA as a stable end product from histidine via urocanic acid and 4-imidazolone-5-propionic acid (ImOPA) in mammals and man (Fig. 3). ImOPA is a highly unstable intermediate which is hydrolyzed spontaneously in vitro at $\mathrm{pH} 7$ (10). In vivo, this compound is hydrolyzed to FIGlu by imidazolonepropionase or oxidized to HPA by aldehyde oxidase (EC. 1.2.3.1) (11), a flavohemoprotein containing molybdenum. Intraperitoneally administered HPA is excreted completely and unchanged within 12 hr (8). We did not attempt to measure HPA or FIGlu in plasma, nor did we attempt to detect ImOPA in urine.

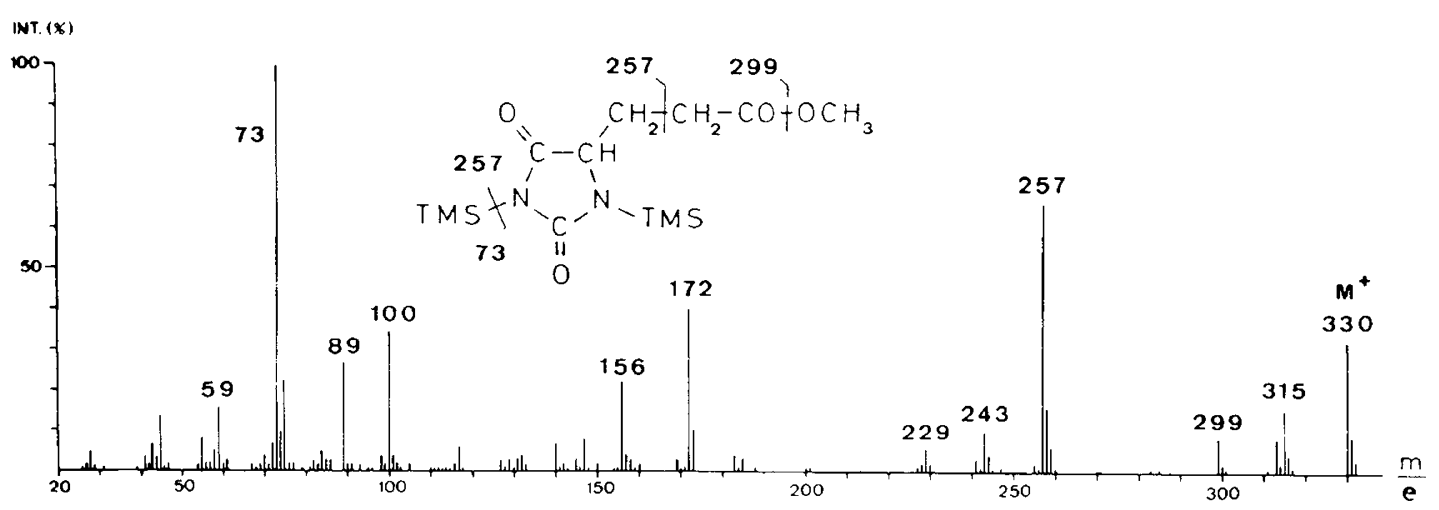

Fig. 1. Electron impact mass spectrum at $70 \mathrm{eV}$ of urinary hydantoin-5-propionic acid as $N, N^{\prime}$-bis-trimethylsilyl $(T M S)$ methyl ester derivative after gas chromatography on $1 \%$ SE-30 at $150^{\circ}$. 


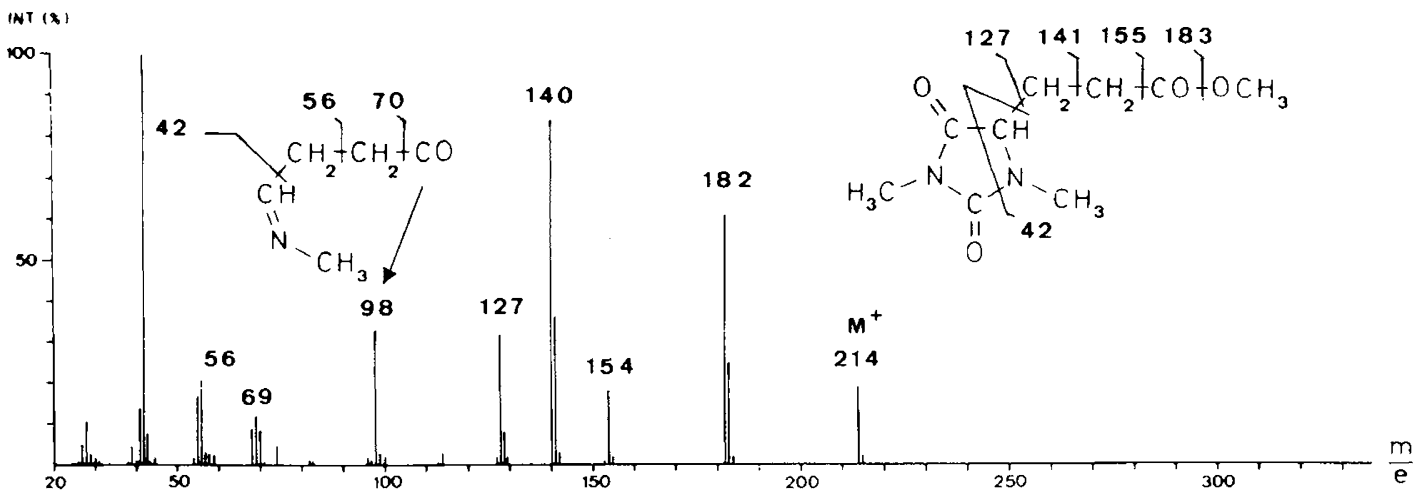

Fig. 2. Electron impact mass spectrum at $70 \mathrm{eV}$ of urinary HPA as $N, N^{\prime}$-dimethyl hydantoin propionic acid methyl ester after gas chromatography on $0.5 \%$ Carbowax $20 \mathrm{M}$ at $180^{\circ}$

Table 1. Excretion of hydantoin-5-propionic acid (HPA) and formiminoglutamic acid (FIGlu) in 24-hr urine before and after loading with free L-histidine in three equal doses of $66 \mathrm{mg} / \mathrm{kg}$ each with $4-\mathrm{hr}$ intervals, in total, $1.276 \mathrm{mmol} \mathrm{His/ \textrm {kg }}$

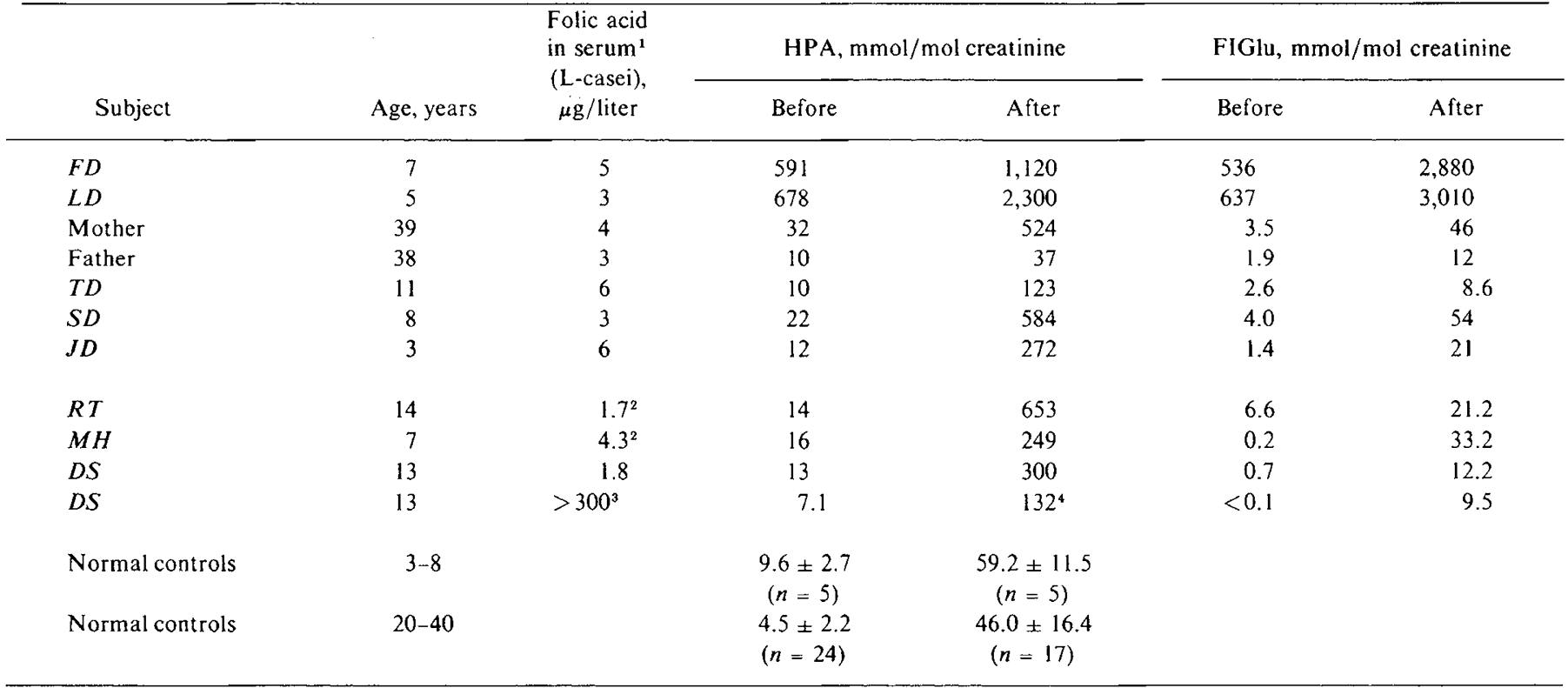

${ }^{1}$ Normal values $3-16 \mu \mathrm{g} /$ liter.

${ }^{2}$ Normal values $6-16 \mu \mathrm{g} /$ liter.

${ }^{3}$ After folic acid administration per os $(10 \mathrm{mg} / 24 \mathrm{hr}$ for 10 days).

'Note the surprisingly high value.

HPA was analyzed quantitatively in human urine by paper and thin layer chromatography, comparing the size and intensity of the spots $(14,18)$. Using the highly specific mass fragmentographic method (16), we found essentially the same range of normal values in micromoles per $24 \mathrm{hr}$ as reported by Middleton in micromoles per $8 \mathrm{hr}$ (14). However, HPA excretion expressed as HPA to creatinine ratio gives a narrower range of normal values and pathologic values can be recognized more easily.

Patients with "formiminotransferase deficiency syndrome" have been reported by Arakawa et al. (1-6) and by Herman et al. (12). All of these seven patients showed quite different clinical symptoms and FIGlu excretion was only about $10 \%$ or less of the amount in our cases (15). In four cases, the formiminotransferase activity was measured by Arakawa et al. (1-5) in liver obtained by biopsy or at autopsy. About $14-54 \%$ of the activity of the controls was found. For ethical reasons no liver biopsy could be performed by us. However, comparison of the FIGlu excretion values for the cases of Arakawa et al. (1-6) and Herman et al. (12) and those reported here suggests that the present cases have much less residual formiminotransferase activity than the patients described by Arakawa et al. and Herman et al. We believe that the published cases of formiminotransferase deficiency syndrome $(1-6,12)$ are a heterogenous group of patients and that the formiminotransferase deficiency is not directly or entirely responsible for their varying clinical symptoms. This assumption (15) has now been confirmed by the report of Perry et al. (17) of two new cases which resemble our cases in the amount of FIGlu excretion, normal serum folate, normal hematologic findings, and practically no mental retardation. The retarded speech development in patient $F D$ and in the patient reported by Perry et al. (17) is of interest in relation to the reported speech defect in some cases of histidinemia (histidine ammonia lyase (EC. 4.3.1.3) deficiency).

HPA has not been measured earlier in a patient with formiminotransferase deficiency syndrome. The very high basal value of HPA in $F D$ and $L D$ (Table 1) could be explained easily by the assumption of an accumulation of imidazolone propionic acid due to a nearly complete formiminotransferase deficiency, and consequent overflow in the direction of HPA. It is remarkable that the basal values of HPA and FIGlu are comparable: the mean value of $F D$ and $L D$ per mole of creatinine is $635 \mathrm{mmol} \mathrm{HPA}$ and 586 mmol FIGlu. However, after loading with histidine, the corresponding mean values are $1,710 \mathrm{mmol} \mathrm{HPA}$ and $2,940 \mathrm{mmol}$ 


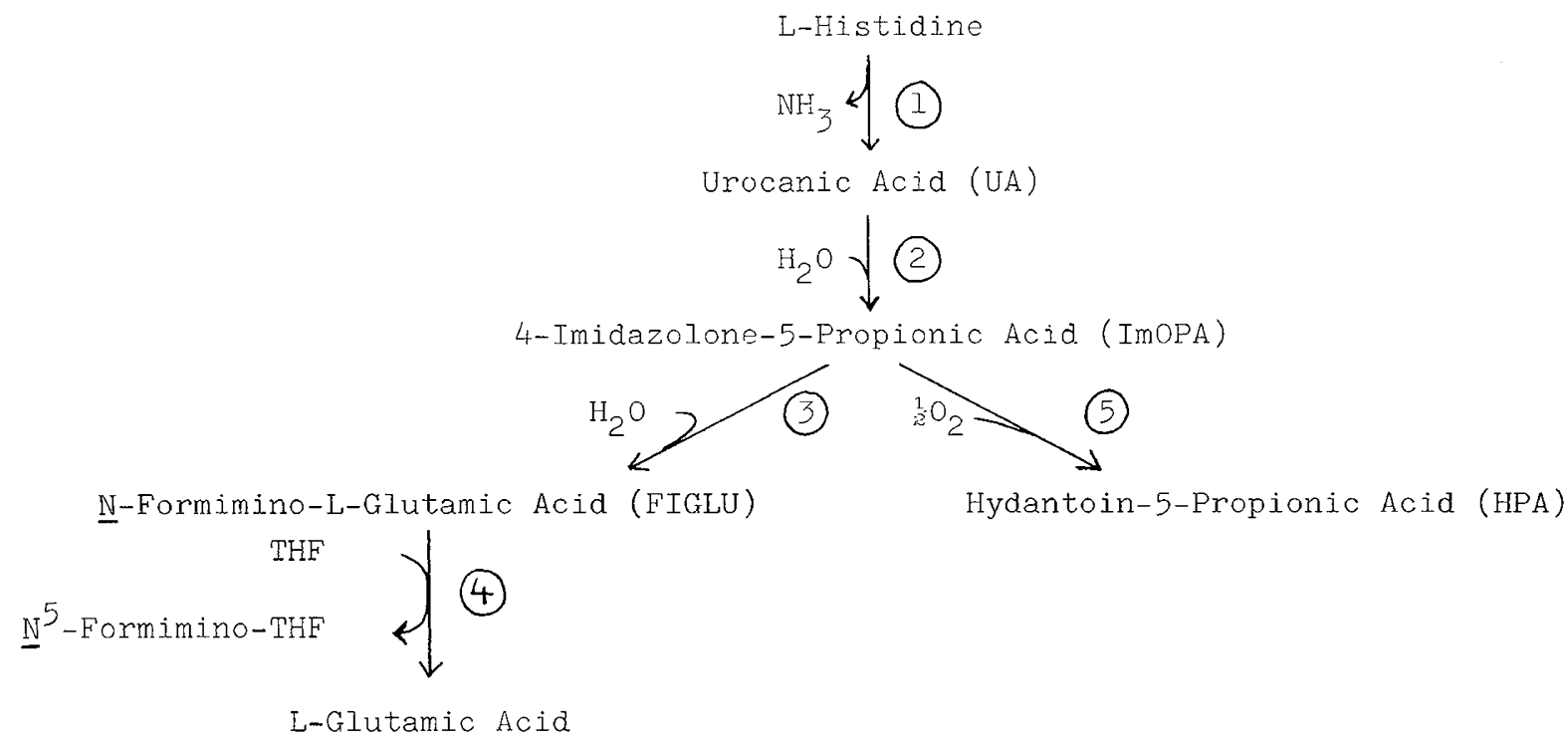

Fig. 3. Catabolism of L-histidine to glutamic acid and hydantoin-5-propionic acid, respectively. THF: tetrahydrofolate; (1): histidine ammonia-lyase (EC. 4.3.1.3); (2): urocanate hydratase (EC. 4.2.1.49); (3): imidazolonepropionase (EC. 3.5.2.7); (4): glutamate formiminotransferase (EC. 2.1.2.5); (5): aldehyde oxidase (EC. 1.2.3.1.).

FIGlu. The lower increase of the excretion of HPA may indicate a partial saturation of the oxidase reaction system and a more efficient imidazolonepropionate hydrolase system.

The high HPA excretion of the other members of the family may indicate heterozygosity. After histidine loading, only the value for the father is within the range of our control subjects, whereas FIGlu excretion is normal in $T D$ and $J D$. Thus, HPA excretion may be a more sensitive criterion than FIGlu excretion to detect such an abnormality. On the other hand, our range of normal values for HPA may be too narrow. However, the father's normal response to the histidine load may imply that heterozygotes cannot be identified under our conditions.

Our results in patients with folic acid deficiency confirm the proposal that abnormally high HPA excretion after histidine loading indicates folic acid deficiency $(14,18)$. HPA measurement seems to be a valuable supplement and even may be a more sensitive alternative to enzymatic FIGlu measurement for the detection of folate deficiency or impaired folate utilization.

\section{SUMMARY}

Hydantoin-5-propionic acid was detected in massive amounts in the urine of two previously described sisters with folic acid nondependent formiminoglutamic aciduria. HPA was identified rigorously, e.g., by gas chromatography-mass spectrometry, and was measured quantitatively by selected ion monitoring (mass fragmentography) using deuterated HPA as internal standard.

Before histidine loading, both girls with the postulated formiminotransferase deficiency excreted an amount of HPA more than 50 times greater than the control subjects. After histidine ingestion, HPA excretion was still doubled or tripled. With the exception of the father, the values for the other members of the family also markedly exceeded the normal range and were of the same order of magnitude as in folate deficiency.

Measurement of HPA excretion in urine seems to be a valuable supplement or alternative to the enzymatic FIGlu test for the detection of general or functional folate deficiency or impaired folate utilization and it will be indispensable for the detection of (as yet unknown) 4-imidazolone-5-propionic acid hydrolase deficiency.

\section{REFERENCES AND NOTES}

1. Arakawa, T., Ohara, K., Kudo, Z., Tada, K., Hayashi, T., and Mizuno, T.: Hyperfolic-acidemia with formiminoglutamic aciduria following histidine loading. Tohoku J. Exp. Med., 80: 370 (1963).

2. Arakawa, T., Ohara, K., Takahashi, Y., Ogasaware, J., Hayashi, T., Chiba, R. Wada, Y., Tada, K., Mizuno, T., Okamura, T., and Yoshida, T.: Formiminotransferase-deficiency syndrome: A new inborn error of folic acid metabolism. Ann. Paediat., 205: 1 (1965)

3. Arakawa, T., Tamura, T., Higashi, O., Ohara, K., Tanno, K., Honda, Y., Narisawa, K., Konno, T., Wada, Y., Sato, Y., and Mizuno, T.: Formiminotransferase deficiency syndrome associated with megaloblastic anemia responsive to pyridoxine or folic acid. Tohoku J. Exp. Med., 94: 3 (1968).

4. Arakawa, T., Tamura, T., Ohara, K., Narisawa, K., Tanno, K., Honda, Y., and Higashi, O.: Familial occurrence of formiminotransferase deficiency syndrome. Tohoku J. Exp. Med., 96: 211 (1968).

5. Arakawa, $T$., and Wada, Y.: Urinary AICA (4-amino-5-imidazole-carboxamide) following an oral dose of AICA in formiminotransferase deficiency syndrome. Tohoku J. Exp. Med., 88: 99 (1966).

6. Arakawa, T., Honda, $\mathrm{Y}$., and Yoshida, T.: Increase in serum folate following an oral histidine load. Tohoku J. Exp. Med., 108: 239 (1972).

7. Bergmann, F.. and Dikstein, I.: New methods for purification and separation of purines. Methods Biochem. Anal., 6: 88 (1958).

8. Brown, D. D., and Kies, M. W.: The mammalian metabolism of L-histidine. I The enzymatic formation of L-hydantoin-5-propionic acid. J. Biol. Chem., 234: 3182 (1959).

9. Brown, D. D., Silva, O. L., McDonald, P. B., Snyder, S. H., and Kies, M. W.: The mammalian metabolism of L-histidine. [1I. The urinary metabolites of L-histidine- ${ }^{14} \mathrm{C}$ in the monkey, human, and rat. J. Biol. Chem., 235: 154 (1960).

10. Dakin, H. D.: XXXVII. On amino acids. II. Hydroxyglutamic acid. Biochem. J. 13: 398 (1919)

11. Hassall, H., and Greenberg, D. M.: Studies on the enzymic decomposition of urocanic acid. VI. Properties of the enzyme catalyzing the oxidation of 4(5)-imidazolone-5(4)-propionic acid to L-hydantoin-5-propionic acid. Arch. Biochem. Biophys., 125: 278 (1968)

12. Herman, R. H., Rosenweig, N. S., Stifel, F. B., and Hermann, Y. F.: Adult formiminotransferase deficiency: A new entity [Abstract]. Clin. Res., 17: 304 (1969).

13. Luhby, A. L., and Cooperman, J. M.: Folic acid deficiency in man and its interrelationship with vitamin $B_{12}$ metabolism. Adv. Metabol. Disord., 1: 263 (1964).

14. Middleton, J. E.: Detection by paper chromatography of imidazoles, including hydantoin-5-propionic acid, in urine after histidine dosage. J. Clin. Path., 18: 605 (1965)

15. Niederwieser, A., Giliberti, P., Matasović, A., Pluznik, S., Steinmann, B., and Baerlocher, K.: Folic acid nondependent formiminoglutamic aciduria in two siblings. Clin. Chim. Acta, 54: 293 (1974).

16. Niederwieser, A., Matasović, A., Kempken, B., and Kojer, E.: Selected ion monitoring of hydantoin-5-propionic acid. Urinary histidine metabolites before and after L-histidine loading and, fasting. Clin. Chim. Acta (in press).

17. Perry, T. L., Applegarth, D. A., Evans, M. E., Hansen, S., and Jellum, E.: Metabolic studies of a family with massive formiminoglutamic aciduria. Pediat. Res., 9: 117 (1975) 
18. van Roon-Djordjevic, B., and Cerfontain-van Staalen, I.: Urinary excretion of histidine metabolites as an indication for folic acid and vitamin $B_{12}$ deficiency. Clin. Chim. Acta, 41: 55 (1972).

19. 2,4,4- $\left[{ }^{2} \mathrm{H}_{3}\right]$-DL-Glutamic acid is available from Sharp \& Dohme, GmbH, D-8 München 80 , Leuchtenbergring 20, Germany.

20. We are indebted to Drs. E. Scarpetta and R. J. Steinmann for their kind collaboration.

21. This work was supported by the Schweizerische Nationalfonds zur Förderung der wissenschaftlichen Forschung, Projects nos. 3.3170.74 and 3.3050.74.

22. The present address of PD Dr. K. Baerlocher is: Ostschweizerisches Kinderspital, St. Gallen, Switzerland.

23. Requests for reprints should be addressed to: PD Dr. A. Niederwieser, Med.-Chem. Abteilung, Universitäts-Kinderklinik, CH-8032 Zürich, Steinwiesstr. 75, Switzerland.

24. Accepted for publication November 17, 1975
Chimeric calf enzyme replacement therapy lysosomes $\alpha$-mannosidase mannosidosis

\title{
Enzyme Replacement Therapy-An Experiment of Nature in a Chimeric Mannosidosis Calf
}

\author{
R. D. JOLLY, ${ }^{(26)}$ K. G. THOMPSON, C. E. MURPHY, B. W. MANKTELOW, A. N. BRUERE, AND B. G. \\ WINCHESTER \\ Faculty of Veterinary Science, Massey University, Palmerston North, New Zealand and Department of \\ Biochemistry, Queen Elizabeth College, University of London, England (BGW)
}

\section{Extract}

This paper describes an experiment of nature involving a chimeric calf with mannosidosis which had obtained a natural transplant of lymphocytes from its normal twin during fetal development as a result of fusion of the placentas. Karyotyping of 200 peripheral blood lymphocytes showed that $77 \%$ were $60, \mathbf{x x}$ and $23 \% 60, x y$. The $\alpha$-mannosidase $\mathrm{pH}$ dependence activity profiles obtained for the chimera were similar to those for a mannosidosis calf in brain, liver, kidney, and plasma but for peripheral lymphocytes and lymph node extracts enzyme activities approaching those of the normal control calf were measured at $\mathrm{pH}$ 4.0-4.3. In the chimera, vacuolation of macrophages and fixed reticuloendothelial cells in lymph nodes and of pancreatic exocrine cells was considerably less than was observed in any of the 35 other calves with mannosidosis. There were considerably fewer oligosaccharides in the brain, lymph node, and liver of the chimera calf than in any of the five mannosidosis control calves. There is little doubt that the $\alpha$-mannosidase produced by the population of normal cells influenced the pathology of the disease, but failure to significantly prevent the eventual clinical course even under these favorable transplant conditions is indicative that tissue or organ transplants are unlikely to be a successful cure for diseases with severe neurologic manifestations. If this disease had been purely visceral then it is postulated that the transplant would have been reasonably effective.

\section{Speculation}

Although acidic $\alpha$-mannosidase supplied by a natural transplant of lymphocytes, and perhaps other cells, was unable to cure or prevent all clinical manifestations of mannosidosis, the therapeutic effect noted in visceral organs indicates that transplants may be an effective means of treating some inborn errors of lysosomal catabolism that occur without severe neurologic involvement. The reduction of storage material within the brain of the chimera suggests that larger amounts of exogenous enzyme supplied over a prolonged period might be more effective in storage diseases with neurologic manifestations. If it can be established that a concentration gradient for storage material exists between certain tissues and tissue fluids then it may not be essential to actively deliver enzyme to the central nervous system.

Recent advances in prenatal diagnosis of inborn lysosomal disorders and the detection of heterozygous individuals have improved the opportunity for control of these inherited diseases. Despite this progress, children will continue to be born with diseases of this type and will need whatever treatment is available. Specific therapy must include an alternative means of degrading the storage material, either by enzyme replacement or by activating the product of the defective gene. The replacement of an enzyme may be attempted either by parenteral infusion of a purified enzyme preparation or by an organ or tissue graft which would then provide a continuous endogenous supply of the required enzyme. With a few exceptions empirical attempts at therapy have not been encouraging and if specific therapy is to be successful, then it is likely to follow the gradual accumulation and analysis of data from specific experiments. This paper describes an experiment of nature involving a chimeric calf with mannosidosis which had obtained a natural transplant of lymphocytes from its normal twin during fetal development as a result of fusion of the placentas.

Mannosidosis is a relatively common inherited lysosomal storage disease of Angus cattle associated with the deficiency of acidic $\alpha$-mannosidase ( $\mathrm{pH} 4.3$ ) and the consequent storage of oligosaccharides containing mannose and $\mathrm{N}$-acetylglucosamine. $(8,10,19)$. The calf in question was recognized during a mass screening program aimed at controlling the disease by identifying heterozygous animals in Angus bull breeding herds in New Zealand (11-13), and was further investigated as part of a continuing program using bovine mannosidosis as a model lysosomal storage disease. 